International Journal of Solar Thermal

Vacuum Engineering

Journal homepage: www.akademiabaru.com/stve.html

ISSN: $2716-6953$

\title{
Manifestations of carbon capture-storage and ambivalence of quantum-dot \& organic solar cells: An indispensable abridged review
}

\author{
Saim Memon ${ }^{1,}{ }^{*}$, Gemeda Olani Nemera ${ }^{1}$, Tochukwu Israel Nwokeji ${ }^{1}$ \\ Solar Thermal Vacuum Engineering Research Group, London Centre for Energy Engineering, School of Engineering, London South Bank \\ University, London, United Kingdom
}

\section{ABSTRACT}

This study bestows an essential abridged review of the manifestations of carbon capture \& storage (CCS) systems and the ambivalence of quantum-dot \& organic photovoltaic (PV) solar cells. This research implicates that CCS system is evolving in capturing $\mathrm{CO}_{2}$ emissions from coal-fired electrical power stations to further mitigate climate change. Different manifestations are discussed for capturing and storing the $\mathrm{CO}_{2}$ with repercussions on operating costs, toxicity and energy efficiency. Chemical Looping Combustion appears to be the more energy efficient than Oxy-fuel CFBC and lonic Liquids, and less expensive than Calcium Looping and Amine Scrubbing. Calcium Looping (Cal) and lonic Liquids are also less toxic than Amine Scrubbing. Direct air technology is also very compelling at capturing $\mathrm{CO}_{2}$ emissions but highly expensive. Nevertheless, further research is still required for all CCS systems to be able to implement them widely in existing/new electrical power stations. Waste heat energy recovery systems can be used in conjunction with $\mathrm{CO}_{2}$ capture systems for further reduction of emissions. The ambivalence of quantum dot and organic solar cells are briefly reviewed. It implicates that composite film with enhanced quantum dot effects will make the film highly transparent and options of tunability of its color spectrum make the quantum dot solar cells highly attractive to a wide variety of applications. Organic solar cells are carbon-rich polymers and can be designed to improve a precise function of the cell, such as sensitivity to a certain type of light. OPV cells can only be considered as half-competent to crystalline silicon and have smaller beneficial lifespans, but could be less costly to produce in high volumes. Current research issues are substitution/compromises between electrical power conversion efficiency and average visible light transmittance. However, improving average light-transmittance decreases electrical power conversion efficiency and vice versa.

\section{Keywords:}

Carbon Capture \& Storage; Quantum dot; organic photovoltaic; waste heat energy recovery; coal-fired electrical power stations

Copyright $\odot 2020$ PENERBIT AKADEMIA BARU - All rights reserved

\section{Introduction}

The world is, without the shadow of a doubt, becoming a global pollution village, mainly due to an increase of global population and industrialisation prompted an increase of energy demand [1]. On one hand, climate change needs to be mitigated with progressive technologies and on the other hand global population need electrical energy for their appliances, heating/cooling requirements and

\footnotetext{
* Corresponding author.

E-mail address: $\underline{\text { S.Memon@Isbu.ac.uk }}$
}

https://doi.org/10.37934/stve.2.1.4058 
the related services need in order to satisfy the social and economic development, welfare and health. The adoption of the usage of renewable energy sources can assist with the mitigation of climate change. Such an approach is a vital step toward meeting the energy demands of future generations. However, a demolition of the coal-fired electrical power stations might affect the prosperity and affordability of energy requirement to the vast majority of the global population. It is indeed overwhelming that currently, approximately 1.4 billion people in the world are devoid of electricity and more than $80 \%$ of these people reside in rural areas. Thus, the number of rural communities that rely on the traditional use of biomass is anticipated to reach 2.8 billion by the year 2030 [2].

Carbon dioxide $\left(\mathrm{CO}_{2}\right)$ emissions has long been blamed for climate change [3]. Coal-fired electrical power stations have an environmental responsibility to remove these emissions due to their combustion of coal and other fuels. There are different ways to reduce the $\mathrm{CO}_{2}$ emissions from an electrical power station (i.e. by improving the power station's efficiency so that less coal is burned [4]). However, A Carbon Capture \& Storage System (CCS) is deemed game-changer at reducing the $\mathrm{CO}_{2}$ emissions by specifically lowering the amount of these waste emissions that infiltrate the atmosphere, and instead storing it underground or in a storage site. The CCS system is beneficial in places that emit a lot of $\mathrm{CO}_{2}$ and there are various benefits/drawbacks of a CCS system, for which this paper concisely discussed it. By lowering the amount of $\mathrm{CO}_{2}$ that reaches the atmosphere, CCS systems could help to avoid worsening climate change/global warming. However, to date CCS systems have not been widely used by coal-fired electrical power stations. It is essential to be able to re-use any wasted energy to become more energy-efficient. This is done by using thermoelectric devices that convert wasted heat energy to electrical energy $[5,6]$. Energy-efficiency is a great way to mitigate climate change. There are different systems for recovering wasted combustive heat energy, which can be lost industrially or from coal-fired electrical power stations, electric vehicles and etc [7]. The wasted heat energy can then be used as an energy source instead of being deserted. The first part of the paper is to present the manifestations on critically analysing and reviewing the latest developments of the Carbon Capture \& Storage System (CCS) and waste heat recovery systems.

The second part of this abridged review paper discusses ambivalence of the progressive photovoltaics technologies such as organic photovoltaic solar cells and quantum dot solar cells and how the future of these will help in not only mitigating the carbon emissions but also advancing or modernising the building and electric vehicles glass sheets. As photovoltaic device was first demonstrated back in the 1800's, since then the concept of solar technology was well known [8]. An important technology breakthrough was developed of $p-n$ junction solar cells with silicon, at Bell laboratory, presented as solar battery [9]. Radiation from the sun is seen as the most abundant renewable energy source to human. Alexandre Edmond first recorded photovoltaic effect in the year 1839. Silicon has continued to be the dominating material for photovoltaics technology and developed in a slow but steady fashion over the last 60 years. The latest millennium (2000) technology revolution contributed to massive expansion of silicon, one of the major contributions in the silicon development was subsidy grant in Europe and around the world made to radicalize silicon solar technology, which are still dominating as significant chunk of entire market of photovoltaics (PV) providing its much greater power conversion efficiency at approximately $15-20 \%[8,10]$. An understanding of the photo-physics for organic materials is still evolving, yet comprehensive theoretical models are available for explaining the organic thin film photovoltaic device characteristics from the basics of properties of materials. The operation of the organic photovoltaics (OPV) technology and Quantum Dot is theoretically reviewed and their terminologies of conventionally inorganic $p-n$ junction solar cell to get a qualitative understanding in this paper. An advancement in OPV is being researched which can be itemised as measures to improve device 
efficiency compared to the existing technologies, these are key factors that attracts global commercial interest in organic semiconductors [11], includes (a) ability to be deposited at room temperature on a variety of low cost substrate material (plastic, glass, metal foils), (b) relative ease of processing, (c) material inherently flexibility and readily available, (d) ultra-low cost, and (e) environmentally friendly.

\section{Carbon capture \& storage (CCS) system manifestations}

\subsection{Manifestation of amine scrubbing}

An amine scrubbing manifests slit $\mathrm{f} \mathrm{CO}_{2}$ from flue gas, typically coal, by utilising a chemical solvent [12] and an absorption tower. This method has noticeably been around for a long time and is one of the most achievable approaches to combat global $\mathrm{CO}_{2}$ emissions [13]. It has been mainly used in electrical power stations that are coal-fired [13]. A typical coal-fired power stations are being hinged to mitigate climate change, through the process of separating the $\mathrm{CO}_{2}$, amine scrubbing is an effective solution, with a $75-90 \% \mathrm{CO}_{2}$ capture rate [14]. Innovative Amine Scrubbing technologies 'can capture $\mathrm{CO}_{2}$ with heat duty less than $2.7 \mathrm{MJ} / \mathrm{t} \mathrm{CO}$ and equivalent work less than $250 \mathrm{kWh} / \mathrm{tCO}_{2}$ ' [5]. Nonetheless, this method requires a large quantity of heat to regenerate the amine solvent $(0.72-$ 1.74 $\mathrm{MWt}$ per MWe) [15]. There are alternative configurations of this method that allow for optimisation but for existing coal-fired electrical power stations, output power reductions may be necessary [15]. Recent improvements on the features of amine scrubbing are reversible stripping and advanced stripper configuration. reversible stripping achieves a difference with $\mathrm{CO}_{2}$ loading at 'rich $\left(5 \mathrm{kPa} \mathrm{CO}_{2}\right.$ at $\left.40^{\circ} \mathrm{C}\right)$ and lean $\left(0.5 \mathrm{kPa}\right.$ at $\left.40^{\circ} \mathrm{C}\right)$ conditions' giving an idea of capacity and allowing us to see how efficient this process is in achieving a high $\mathrm{CO}_{2}$ removal. Another improvement to the process is 'advanced stripper configuration', which essentially reduces the heat loss as water vapour by the use of an inter-heated stripper. This configuration is perceived to achieve almost $20 \%$ less energy. Absorption by chemical solvents combined with $\mathrm{CO}_{2}$ long-term storage appears to offer interesting and commercial applicable $\mathrm{CO}_{2}$ capture technology' [16]. However, it is suggested that the amine scrubbing process could better be optimised when used in a large coal-fired electrical power stations in order to meet the 'high regeneration energy cost'.

In particular, the cost of amine scrubbing is considered to be high approximately between 40 and $70 € /$ ton $\mathrm{CO}_{2}$ ) [16]. It influences to the operational and capital cost for coal-fired electrical power stations. However, with a slight diminution in $\mathrm{CO}_{2}$ capture cost can be afforded by the $\mathrm{CO}_{2}$ emission trading credits generated by amine-based capture system [14]. Amine scrubbing may be considered a toxic option [17] for CCS when compared to Calcium Looping due to the use of chemical solvents. The Amine Scrubbing method is yet an effective method for removing $\mathrm{CO}_{2}$ with its high $\mathrm{CO}_{2}$ capture rate, however, it is quite costly and a toxic option as it uses amine solvent chemical. Any typical coalfired electrical power station produces a power of $1000 \mathrm{kWh} / \mathrm{t} \mathrm{CO}_{2}$ released. Thus, by using amine scrubbing method reduces the output power efficiency of about $20-30 \%$, which is a trade-off [12].

\subsection{Manifestation of lonic liquids}

This competing method poses the use of ionic liquids (i.e. ammonium, sulfonium, alkyl sulphate [18]) instead of the chemicals used in Amine Scrubbing. As Amine Scrubbing is 'very energy intensive' and 'due to emissions of the used volatile solvent components' [18], ionic liquids were proposed as an alternative. The use of ionic liquids is actually known to be 'useful for $\mathrm{CO}_{2}$ separation from flue gases' due to various properties such as 'reasonable thermal stability', 'absorption capacity', 'lower vapour pressure', etc. Ionic liquids are flexible in nature and have potential to decrease the cost of 
$\mathrm{CO}_{2}$ capture [18]. Ionic liquids are also easier to recycle [12]. However, 'physical ionic liquids for $\mathrm{CO}_{2}$ capture has lower $\mathrm{CO}_{2}$ absorption capacity at post-combustion conditions [18]. Ionic liquids can be used without water, which reduces energy required for $\mathrm{CO}_{2}$ removal [14]. A relationship described by [12] between the physical properties of the ionic liquids and $\mathrm{CO}_{2}$ solubility, as well as into ion selection, task-specific ionic liquids, and molecular simulations of $\mathrm{CO}_{2}$ with ionic liquids. It appears that the use of ionic liquids may be a better option when compared with Amine Scrubbing due to solving the issue of further emissions from the amine solvent used in Amine Scrubbing. Ionic liquids are more environmentally-friendly (although not all are biodegradable [18]). The use of ionic liquids still has drawbacks, such as the price of ionic liquid solvents. For example, 'the price/performance ratio of existing ionic liquids is still insufficient to compete with existing commercial solvents at a rate of $\sim 1000 \$ / \mathrm{kg}^{\prime}[19]$.

\subsection{Manifestation of Calcium looping, CaL}

This method is an improved version of Carbonate Looping. Calcium looping removes $\mathrm{CO}_{2}$ 'from the exhaust of a coal-fired electrical power station, generating a pure stream of $\mathrm{CO}_{2}$ ready for geological sequestration' [20]. The calcium looping CCS system uses CaO 'as a regenerable sorbent of $\mathrm{CO}_{2}^{\prime}$ [12]. The basic process involves a very high heat in the calcination of solid calcium. This allows for thermal decomposition into a gas form of $\mathrm{CO}_{2}$ and solid form of $\mathrm{CaO}$, giving a stream of carbon dioxide which is purified and ready for use/storing [20]. This 'calcination' part of the process is also accompanied with a 'carbonation step' [12], which is a similar reaction but in reverse [20] and allows for the carbon dioxide level to be reduced within the flue gas. Both steps use extremely high temperatures of up to $900^{\circ} \mathrm{C}$ [12]. Updates to the Calcium Looping method include a possibly different material in order to improve the operation of this system [12]. Post-combustion Calcium Looping has been successful in pilot plants [16], particularly in Spain. According to [17], calcium looping is deemed as less toxic than amine scrubbing, so, a better option for mitigating toxicity. This is likely due to the chemical used in amine scrubbing, as compared with the limestone used in Calcium Looping [21]. As electrical power stations generate power, and this is the least toxic method of 'decarbonation of power generation' [22], this appears as the better solution. Further to this, it doesn't require a scrubbing tower, as with amine scrubbing, [20] and the sorbent is economical, costwise. However, the $\mathrm{CO}_{2}$ capture rate is comparatively lower at around 85\% [23], and therefore, a less effective method for electrical power stations to help mitigate climate change. Additionally, as the process involves a direct reaction with calcium oxide, electrical power stations would require an ability to produce large amounts of high purity oxygen [23] for this process, which may not be feasible for every electrical power station. Electrical power stations would also need to pay the high set-up costs for this particular CCS method. Nevertheless, there is potential going forward to improve this CCS method and its running costs to make it more attractive for electrical power stations to implement and utilise in the hopes of mitigating climate change.

\subsection{Manifestation of direct air capture technology}

This method is described as removal of $\mathrm{CO}_{2}$ emissions from the 'air and generating a concentrated stream...for reuse' [24]. The wet air capture type is 'the most developed approach' [12] and uses 'aqueous sodium hydroxide ( $\mathrm{NaOH}$ )-based solutions' (soda/lime), and the dry air type uses 'solid organ amine- based adsorbents' [24]. The most recent proposed change to the wet air capture type is the one that 'involves direct causticisation with titanates' - requiring less energy [24]. Reducing the energy demand can lessen the mitigation costs [12] making it a better contender in the 
climate change mitigation tools. This type of $\mathrm{CO}_{2}$ capture is extremely helpful in mitigating climate change as it can be used to 'adjust the atmospheric $\mathrm{CO}_{2}$ ' in the event of 'atmospheric greenhouse gas inventory reaching dangerous levels'. Therefore, direct air capture may be able to reduce climate change by literally altering the atmosphere and reversing atmospheric pollution to the environment. Direct Air Capture 'removes emissions from any part of the economy with ease' and it 'it permits reduction in concentrations faster than the natural carbon cycle' [24]. In more recent times, there are more cars on the roads, and these are constantly creating emissions. Many researchers propose that direct air capture could possibly be used for tackling this particular cause of worsening climate change going forward [12,24]. However, one factor stopping this being implemented widely at present is the high energy and monetary costs attached to this particular method, which could be an issue for Electrical Power Stations. Researchers highlight the need to deploy other less costly methods first as this is a very expensive option for mitigating climate change. Therefore, electrical power stations should consider alternative methods and use this as the last option. [25] agrees with this notion in that it sees Direct Air Capture as a 'risky policy decision' with regard to high costs, and also states that the transport sector is a better place for use of this technology. To clarify, Direct Air Capture is not considered a great option for electrical power stations as they are 'large fixed-point sources' and Direct Air Capture is better used for 'global atmospheric concentrations'/large scale removal [24].

\subsection{Manifestation of Chemical-looping combustion}

This method involves 'oxidizing fuels without the direct use of either air or oxygen' [26]. Using this approach, 'the fuel (usually natural gas), is oxidized by an oxygen carrier, which is then regenerated by reaction in air' [26]. The oxygen carrier that assign oxygen from combustion air to the fuel meaning air and fuel do not directly contact each other [27]. There are 'two interconnected fluidized beds, i.e. fuel reactor and air reactor' [27]. Within the fuel reactor, there is usually only $\mathrm{CO}_{2}$ and $\mathrm{H}_{2} \mathrm{O}$ and 'slight production of nitrogen oxides (Nox), so that after condensation of the water' [28], there will be a pure stream of $\mathrm{CO}_{2}$. Research has shown that $\mathrm{Ni}$ is one of the suitable options for the carrier and that this method is a 'low cost $\mathrm{CO}_{2}$ capture' approach [28]. This system of carbon capture and storage is deemed as the most energy-efficient form, as no energy is 'expended for the gas separation' [12] meaning almost all carbon is captured. Unlike Calcium Looping, this method does not need large amounts of pure oxygen that 'require higher power consumption for $\mathrm{CO}_{2}$ generation' [27]. The lesser amount of energy required for this method means that there will be no energy penalty for electrical power stations, and it is an attractive option for it to use in order to mitigate climate change as an abundance of energy/costly equipment is not required.

$\mathrm{CO}_{2}$ Can be effortlessly retrieved in this method 'by condensation of the water vapor without any extra cost' [27], unlike CCS systems that use absorption. The performance of Chemical Looping Combustion against Calcium Looping Combustion in coal-based power plants (power stations) was analysed by [29]. It was found that Chemical Looping combustion was a more efficient system for removing pre-combustion $\mathrm{CO}_{2}$. Nevertheless, both methods were more efficient than solvent-based methods, and (i.e. capital and electricity) costs were lower. According to [30], out a $100 \% \mathrm{CO}_{2}$ capture rate for IGCC-CLC (Integrated Gasification Combined Cycle-Chemical Looping Combustion) post combustion technologies. With the 'modification of IGCC-CLC into CDCLC (Coal Direct Chemical Looping Combustion) tends to increase the net electrical efficiency by $4.7 \%$ while maintaining $100 \%$ $\mathrm{CO}_{2}$ capture rate' [30]. Therefore, to mitigate climate change, this is a very effective CCS system, as it is energy-efficient and has lower cost compared to other systems. As energy-efficiency is more environmentally-friendly. Recently, there has been a research [31] on this method carried out into 
scaling up this technology, the use of different materials for the carrier, and CLC with the use of solid fuels. In which, the fuel is introduced to the fuel reactor in a gaseous form where it reacts with the oxygen carrier. The reduced metallic oxide will then be scattered in to the air reactor where it is going to be oxidized and regenerated. When comparing this particular technology for $\mathrm{CO}_{2}$ separation with others discussed earlier in a power process with natural gas as the fuel, has a sufficient reduction in the efficiency of $12-19 \%$ [32].

\subsection{Manifestation of Oxy-fuel combustion technology}

This is the leading method and most developed method. The process 'involves burning the fuel with nearly pure oxygen instead of air' [33]. Further to this, 'in order to control the flame temperature, some part of the flue gas is recycled back into the furnace/boiler' [33]. The main concept is that it uses nearly pure oxygen, meaning that the final flue gases is mostly concentrated in $\mathrm{CO}_{2}$ and water and easier to purify/store. During the boiler stage of this process (where oxygen and fuel is heated), the steam produced can be used to power the turbines. According to [4] concedes that it is the most promising CCS method as 'due to the high flue gas $\mathrm{CO}_{2}$ concentration, it does not require $\mathrm{CO}_{2}$ separation'. This avoids power station losses, in terms of efficiency. This method also allows for lower equipment and costs for operation as with this method 'four-fold reduced flue gas volume' occur by using oxygen for combustion instead of air. According to [29], they discovered Oxyfuel Combustion in combination with IGCC (integrate gasification combined cycle) that can reach a $\mathrm{CO}_{2}$ capture rate of $99 \%$ and better efficiency [34]. This means that the power station could be almost completely free of $\mathrm{CO}_{2}$ emissions, resulting in a very little negative impact on climate change. However, this idea based on future IGCC plants and does not take consideration into approaches for existing power stations. It implicates that by the recycling of the flue gases (RFG), which is a key element of Oxy-fuel Combustion, realistically 'increases the cost of the process' [35]. Though, remaining $\mathrm{CO}_{2}$ can be purified at a lower cost by using a cryogenic air separation unit to allow 'high purity oxygen to be mixed with RFG (Recycling Flue Gases) prior to combustion to maintain combustion conditions' [35]. These materials will then be able to tolerate elevated temperatures. Although this is a promising method but the perceived costs vary greatly, especially between different counties [36]. Nevertheless, this system requires the power station to have a 'recycle loop, $\mathrm{CO}_{2}$ purification' and cause an energy penalty because of 'the requirements of producing $\mathrm{O}_{2}$ and compressing $\mathrm{CO}_{2}^{\prime}$ [12]. Plant efficiency was reported to be reduced [36]. Therefore, although it is deemed as the most interesting method to date, it still has many drawbacks that make it an unattractive option for mitigating climate change.

\subsection{Manifestation of Oxy-fuel Circulating Fluidised Bed Combustion (CFBC)}

This method is similar to Oxy-fuel combustion, but the difference is that it involves circulating fluidised bed combustion (CFBC) [12]. The process involves 'the fuels being burned in a turbulent bed of an inert material, thus ensuring high heat transfer rates, and good solid mixing.' [12]. However, unlike Oxy-fuel combustion, where '70-80\% of the flue gas must be recycled, lower levels of flue gas recirculation are possible' [12] allowing for flexibility in size of the system. Therefore, higher cost savings. This method is currently widely used in the power industry [12] and there have since been many pilots of this approach for $\mathrm{CO}_{2}$ capture, with numerous experimental results on emissions, etc. There is also a demonstration unit of this system in Spain, with plans to build a larger scale unit [36]. It is so far a good indicator of the performance of this method. A successful 3-year $\mathrm{O}_{2} \mathrm{GEN}$ project 
developed a 2nd generation oxy-fuel circulating fluidized bed power station and focused on 'higher oxygen concentrations with the aim of decreasing flue gas recirculation and the energy penalty' [37].

The air separation and also the compression and purification components were improved and as a result, energy consumption was reduced. Another area of improvement was the efficiency, which was achieved through integration methods. This was a key milestone for Oxy-fuel CFBC. Foster Wheeler, who is known for bringing CFBC to commercial level is currently involved with ENDESA to develop a supercritical CFBC that will capture $90 \%$ of $\mathrm{CO}_{2}$ emissions [3]. Therefore, this is an improved version of Oxy-fuel combustion, and has many advantages such as cost savings, reduced energy consumption, improved efficiency. Thus, the reduced energy consumption, specifically, will have an improved impact on the environment.

\subsection{Manifestation of Low temperature adsorbents}

As $\mathrm{CO}_{2}$ capture systems usually are associated with requiring extremely higher temperatures, there have been proposals for low-temperature means for capturing $\mathrm{CO}_{2}$. The high temperatures were associated with certain drawbacks. The proposed low temperature adsorbents proposed needed to take into consideration the possibility of performance loss, cycle time, hydrothermal stability, cost of equipment, and more [12]. Some proposed adsorbents include zeolites [12] with 'values of the $\mathrm{CO}_{2}$ uptake between 2 and $3 \mathrm{~mol} / \mathrm{kg}$ at $0.1 \mathrm{bar}$, at temperatures between 15 and 35 ${ }^{\circ} \mathrm{C}$.' However, if there is water present, the adsorption performance can be reduced [12]. MOF's, Mesoporous silicas, and carbon-based adsorbents were also proposed, and testing at pilot plants have taken place to determine the effectiveness of the low temperature adsorbents with regards to $\mathrm{CO}_{2}$ capture of more than $90 \%$ [12].

\section{Manifestation of combustive waste heat energy recovery}

There is an increasing interest in harnessing the combustive waste heat energy into a smaller portion of electrical energy by utilising the thermoelectric Peltier modules [38]. However, current research tends to focus more on the thermoelectric materials of the system rather than the design of the system itself. They can be used anywhere where there is wasted heat energy, for example electric vehicles and coal-fired or nuclear power stations. The working principle and primary materials are reported elsewhere [39]. It is pertinent to mention that the energy conversion efficiency with thermoelectric system still needs improvement. Also, a greater potential can be realised with the use of phase change material for storing the waste heat for useful purpose, specifically for the charging of electric vehicles $[40,41,42]$ that subsequently improves the overall charging efficiency. The latest developments include nanomaterials [7], but these are still in the development stage, and system design improvements such as thermoelectric material volume and weight. If higher efficiency thermoelectric systems are manufactured with the progressive technologies such as vacuum thermoelectric then the scope of it can be integrated to coal-fired electrical power stations in conjunction to CCS that will improve overall operational and conversion efficiency. Organic Rankine cycle unit typically recovers wasted heat and transforms it into electricity. It is a variation of the Rankine Cycle Unit. There is also a Supercritical Rankine Cycle Unit that involves supercritical fluid [43]. The difference with the Organic Rankine Cycle Unit system is that it uses an organic fluid and it can also potentially be used in power stations. The process of this system involves this fluid evaporating inside the boiler, before ending up in an expansion device or heat exchanger. One particular article [43] states that in the conversion of low temperature heat into electricity the greatest efficiency is obtained in many cases by using an Organic Rankine Cycle (ORC)' and looks at 
whether the process is possible with high temperature applications and a change in design using a high-speed oil free turbogenerator-feed pump instead. It is an ongoing effort to invent different possible fluids that impact on their performance. According to [44], 'the system efficiency increases and decreases for wet and dry fluids, respectively, and the isentropic fluid achieves an approximately constant value for high turbine inlet temperatures' [44]. Although this system can recover wasted heat energy from thermal processes carried out by industrial power stations and various other places, it has been heavily researched within vehicle applications. According to [45], a well-designed Organic Rankine Cycle system to internal combustion engine can effectively improve the overall energy efficiency and reduce emissions with around 2-5 years payback period through fuel saving. However, this system would need to be tailored to use in electrical power stations to ensure it is as effective as possible.

\section{Ambivalence of quantum-dot \& organic solar cells durability 4.1 Organic solar 'photovoltaic' PV cells}

Currently, organic materials used in solar cell comprise of conducting polymers, dyes, pigments, and liquid crystals [46]. Subsequently, the conductive polymers are also known for their best photo physical properties, conjugated polymers and molecules have their enormous advantage of simplicity. In addition, chemical modification to alter their properties such as the band gap. Molecules with larger molecular weight (>1000amu) are referred as "polymers" [47]. Depending on their molecular structure and chemical composition, polymers can in principle be soluble or insoluble in common solvent organic solar cell conveys carbon-based materials as main constituent of its device rather than silicon. Organic photovoltaics (OPV) is made of compounds mass-produced as a thin roll of plastics [48], with the possibility of storing more solar cell than the predecessors, this recent innovation have paved a new drive in organic photovoltaic technology which would be further combined either with dye sensitized or Quantum Dot [49]. There are four important processes in an organic photovoltaic cell: absorption of light; charge transfer and separation of opposite charges; charge transport and; charge collection [50]. These must be optimised to obtain higher conversion efficiency. More significantly, organic semiconductor can be processed from solution at or near room temperature on a flexible substrate by simple, cheap and low-energy deposition method, such as spin or blade capacity there by yielding cheaper devices, which have to be sealed up to build larger system or seal down to build smaller system. Its unit are in megawatts range or mini range [50]. The normal silicon solar cell technology has aged to a point where by cost discount are generally foreseen, only by the economical measure to rate when compared in calculation to thin film photovoltaics technologies. On the other hand, it situates OPV in no extra or less in the same line with the normal silicon technology. To bridge the gap of economic difference, this create an urgent attention to rectify such with latest revealed technology and the notion for photovoltaic conversion, to reduce the price of solar cell. Present literature [51] worked towards cost reduction by enhancing the device architecture by the use of various semiconductor material such as, silicon, gallium, cadmium, telluride, indium phosphide, arsenide, etc. Considering other proven research making silicon the best-developed solar cell technology, their commitment has proven its level of efficiency to $25 \%$ with crystalline silicon material.

Organic PV, or OPV, cells comprises of carbon-rich polymers and can be designed to improve a precise function of the cell, such as sensitivity to a certain type of light [50]. This technology has the logical potential to deliver electricity at a reduced cost than silicon or thin-film technologies. OPV cells can only be considered as half-competent to crystalline silicon and have smaller beneficial lifespans, but could be less costly to produce in high volumes [52]. They are applicable to a diversity 
of supporting materials, making OPV able to serve a wider assortment of uses. Most semiconductor polymers have a power gap greater than $2.0 \mathrm{eV}(620 \mathrm{~nm})$, this limits the absorption of solar photons around $30 \%$. Recent advances are of the use of carbon nanotubes and fullerenes, graphene as a type of nanostructured material [52] that have been considered highly promising in many applications of OPV due to its excellent electronic optical thermal and mechanical properties.

\subsection{1 working principle}

It is well known that the intensity of solar radiation attaining on the atmosphere of earth is approximately $1353 \mathrm{~kW} / \mathrm{m}^{2}$ at the emitted radiations from the sun's photosphere at $6000 \mathrm{~K}$ temperature [53]. Ultraviolet (UV)-visible part from the sun light is a phenomenon present in organic photovoltaics that contributes about $10 \%$ of the total light output of the sun, majorly organic semiconductor is able to convey electric current and absorb light. This pose a unique difference to the present-day inorganic semiconductor materials [50]. The charge movement of organic materials at numerous extents is reduced as compared to that of inorganic compounds. A slow movement in organic semiconductor are partly composed by their relatively strong absorption coefficient (i.e. $\geq$ $10^{5} \mathrm{~cm}^{-1}$ ), which permit large absorption in $\leq 100 \mathrm{~nm}$ thick devices [54]. Another great dissimilarity between organic and inorganic semiconductor is that in inorganic materials light absorption (primary photoexcitation) generates free charges, separated at junction. While in organic materials, the result of the photoexcitation are electron hole pairs called Exciton. The Exciton are neutral excited states, with typical binding energy from 0.05 to $>1 \mathrm{eV}[48,54]$. The Exciton diffusion length is typically 5$15 \mathrm{~nm}$; this is also in line towards their route of diffusion between decaying either radioactively or non-radiatively to ground state. In order to distinguish disordered organic materials and organic materials during photoconversion, organic solar cell operate in drift mode, while the functioning of crystalline silicon works on devices based on diffusive mode. Germinate pairs, describes the whole conversion process of sunlight into electricity by organic solar cell through intermediate charge separation approach. This requires strong application of electric field in order to split into free charge carriers [11]. This summary the five basic photovoltaic process which is made up of the following: photon absorption, with the formation of an excited state i.e. electron hole pair, exciton migration to a diffusion zone, charge separation takes place, charge transport to respective electrodes and collection of the charges by the electrodes.

\subsubsection{Architectures}

The variation between the normal organic solar cell architectures lies usually in exciton splitting process. This takes place at different locations within the photovoltaic layer consists of single, bilayer heterojunction, multilayer heterojunction and bulk heterojunction.

\subsubsection{Single layer}

A single organic layer, typically thermally evaporated, sandwiched between two metal electrodes with different metal electrodes with different working function. The charge separation requires a Schottky barrier at one of the organic electrode interfaces and the generated electric field is seldom sufficient to dissociate the Photogenerated excitons [48]. However, electrons tend to recombine with holes rather than to reach the electrode, its efficiency is $0.3 \%$ around the holes rather than to reach at the electrode. Its efficiency can be resolved with the introduction of multilayer organic photovoltaics. 


\subsubsection{Bilayer heterojunction}

The concept of Tags cell is a bilayer device with efficiency of 1\%, where donor / acceptor material is stacked together to form an organic heterojunction. A proper alignment of the energy levels between the donor and acceptor layer is fundamental for efficient exciton dissociation, the bilayer is sandwiched between two electrode whose working function match the donor HOMO and LMU, to facilitate the extraction between respective electrode. An advantage of bilayers as compared to when single cell is monomolecular charge transport after the exciton disassociation. In this, electron transport through the n-type acceptor (electron transport layer ETL) and hole through the $\mathrm{p}$-type donor material (hole transport layer HTL), which allows effective separation of the charge, with great reduction towards charge recombination [55]. A bilayer solar cell can be extracted with several heterojunctions introduced in a cell that could be led to the so-called multilayer solar cell, where additional layers are added to the donor and acceptor. This layer does not improve photocurrent generation, but perform a different function in the cell, using buffer layer as keynote, it encourages hole (electron) accepting/transport/blocking properties [56].

\subsubsection{Bulk heterojunction}

Bulk heterojunction is an interpenetration network of both phases in a mixed form. When surface area of the interface increases, the exciton can dissociate within the bulk. This process changes the two-dimensional interface of the bilayer approach being exchanged by a three -dimensional interpenetration network. Its first efficiency was $1 \%$ but currently from findings have been improved between $4 \%$ to $7.9 \%$. The key interest arises in their reasonably high efficiency, low-cost and easy to fabricate features [57]. The readiness of this takes the processing techniques such as spin-coating, doctor blading, screen printing, inkjet printing and spray coating, this printing techniques. These are considered as one of the most alternative method, since it enables roll-to-roll fabrication of flexible material with large area while thin mechanics and operation principle are complex and not completely verified yet the preparation is simple.

\subsubsection{Buffer layers}

Considering the difficulty encountered between the interface of organic materials and electrode, due to the charge carrier transport. In order to enhance it, a broadly used resolution is to introduce a thin interlayer, called buffer layer, these have numerous functions [54,57]. Between them, it adjusts the electronic performance of the adjacent materials; it guards the organics from the diffusion of the electrode, and hinder the untimely drop of oxygen and / or water molecules.

\subsubsection{Characteristics}

- Photogenerated excitation ('excitons') are strong bounds and do not spontaneously dissociate into charge pairs. (Dissociates require an input of energy of $\sim 100 \mathrm{meV}$ to a few meV for a crystalline semi-conductor. This means that carrier generation does not necessarily result from the absorption of light.

- Charge transport proceeds by hopping between localized states, rather than transport within a band, and Mobility's are low.

- The spectral range of optical absorption is relatively narrow compared to the solar spectrum. 
- Absorption coefficient are high $\left\{10^{7} \mathrm{~cm}^{-1)}\right.$ so that high optical densities can be achieved, at peak wavelength with films less than $100 \mathrm{~nm}$ thick.

- Many materials are susceptible to degradation in the presence of oxygen or water.

- As one-dimensional semiconductors, their electronics and optical properties can be highly anisotropic. This is potentially useful for device design. [49].

The initial throw above due to intermolecular van der Waals forces in organic solids are weak compared to bonds in inorganic crystals and much weaker than the intramolecular bonds. Low mobility is 'made worse' by the high degree of disorder present in many organic solids [49]. The optical excitations accessible to visible photons are usually $\pi$-to- $\pi$ transitions. Most conjugated solids absorb in the blue green; absorption in the red or infrared is header to achieve. However, the absorption bandwidths depend on the degree of conjugation and wider spectral sensitivity can be achieved in highly conjugated dye molecule.

Following properties impose some constrain on organic photovoltaic devices [58].

- A strong driving force such as an electric field should be present to break up the Photogenerated Exciton.

- Low charge carrier mobility's limits the useful thickness of devices.

- Limited light absorption across the solar spectrum limits the photocurrent.

- Very thin devices mean interference effect can be important [59].

- Photocurrent is sensitive to temperature through hopping transport.

\subsection{Quantum-dot solar cells}

A Quantum Dot solar cell is described as a solar cell that incorporates quantum dots as its absorbing photovoltaics material. It was invented as a medium to replace bulk materials such as silicon, copper, indium gallium selenide (CIGS) or CdTe. Quantum dots exhibits band gap that are tunable across wide range of energy range by varying the dots' size. This property makes quantum dot outstanding and beneficial for multi-junction solar cell, which enables its different ranges to enhance efficiency, through harvesting multiple portions of the solar spectrum. Quantum dots are semiconducting element that have been made smaller in size to exciton Bohr radius and due to quantum mechanics consideration. Quantum dots can also be referred to as artificial atom [60]. Exciton are that carriers that generate the resultant quantized energy level. This action is being created by the combination of electrons and holes; the excitation is achieved below the bandgap energy. Quantum refinement effect represents behavioural variation into strong and weak stages of confinement of huge material dimension breakdown, to a lesser specific size approaching Exciton Bohr, diameter in relation to degree of coupling with electron and hole Exciton [58].

There are two constituents in the quantum technology that are the practical quantum revolution and the quantum mechanics revolution. The first being practical expresses the importance of Miniaturization i.e. to develop devices to the simplest most reduced state [49]. The essence is to help create devices with length-scales of nanometres that corresponds to the same scale as plank's constant based on quantum principle. The second quantum revolution reminds us about the necessity of to utilize our scientific mind set to manipulate our naturally endowed resources seen within us and turning it into how we want. The need for second quantum revolution through the aid of quantum mechanics contributes enormously towards human mind development to wisely make decisions to reface its environments through Quantum technology to redesign and fit into its environment. This latest technology could be ascribed to the latest invention ranging from 
development of vacuum insulated glazed windows for zero energy buildings, electric vehicles, mobile devices and etc.

\subsubsection{Techniques to establish quantum dot.}

Typically, there are four techniques that can be utilised to establish quantum dot. The transmission electron microscopy is one of the existing methods of quantum dot to perform visual imaging or micrograph at the nanometre is in the transmission electron microscope (TEM). The TEM operates with electron instead of photons, but exhibits same operational method as optical microscope, with condensing and objective lenses, observing the justified resolution of a TEM image, can be as high as $1.5 \AA$, most semi-conductors applicable are Ge and ITO [61]. These two semiconductors matrix represents ITO, poly crystalline nature in view, while the darker region represents the Ge quantum dot. However, an image alone is not enough to estimate micrographs average quantum dot size and size distribution, it is assumed misleading most often by factors lacking sufficient picture of structure affects the result of getting good size distribution of TEM image. The optical absorption technique involves the direct measurement of band gap energy in semiconductor elements with a similar principle of TEM. This technique, as recalled. the predicted blue-shift in the band gap energy by reducing confinement measurement. It also compares the shift between germanium $\mathrm{Ge}$, stating that its effect does not affect semiconductors such as cadmium telluride while comparing the shift of its optical band edge at $0.5 \mathrm{eV}$. Raman vibrational spectroscopy work with a method called Raman's effect invented in 1928, this could be defined as elastics scattering of light by matter. Due to the change in the incident energy is determined by the type of molecule present, the scattered radiation from a sample can be collected and used to help characterise bonding length, strength, and type of molecular bonds inherent in a sample. It is also applicable in monitoring for monitoring the crystalline of material. Raman can be beneficial tools in analytically supporting the existence of quantum confinement effect in quantum dot films, it measures films that contain stress. Photoluminescence spectroscopy is an experimental measurement to probe the energy level in a quantum dot. It uses laser, tuned to appropriate wavelength; it lets the stick measurement of the change energy states present in the quantum dots [62]. Another benefit of this approach is to regulate the energy state existence in the fabricated structures. One of the recent developments is a Phosphate Buffered Saline (PbS) Quantum Dot that achieved about 3.88\% power conversion efficiency with $22 \%$ average light-transmittance and with Molybdenum trioxide $\left(\mathrm{MoO}_{3}\right)$ achieved $5.4 \%$ power conversion efficiency with $24.1 \%$ average light-transmittance.

Current research issues are substitution/compromises between electrical power conversion efficiency and average visible light transmittance. However, improving average light-transmittance decreases electrical power conversion efficiency and vice versa. A selective wavelength based single junction transparent photovoltaic film has a theoretical Shockley-Queasier (SQ) limit of 20.6\% [63] conversion efficiency at $100 \%$ average visible light transmittance and the conversion efficiency can be increased by adding junctions. However, glass sheet alone has about $92 \%$ average visible light transmittance $[64,65]$, and a typical double air-filled $[66,67,68]$ or vacuum glazing $[69,70]$ has approximately between $70 \%$ and $80 \%$ average visible light transmittance [71] and it would drop to $70 \%$ with the application of a low emissivity (low-e) coating to further reduce the radiative heat transmission. However, the low-e coatings can be avoided or replaced with transparent PV film as the initial research suggests it would not make a huge impact on the thermal transmittance values $[72,73,74]$ since vacuum insulation would be an advantage irrespectively. 


\subsubsection{Applications}

A composite film with enhanced quantum dot loading effect that make the film highly transparent and options of tunability of its colour spectrum make the quantum dot solar cells highly attractive. Specifically, nowadays, there is a huge focus going on developing more energy-efficient transparent photovoltaic films with vacuum insulation [75-79] and the main focus is to improve both the transmission of visible light whilst maximizing the wavelength selective absorption of ultraviolet (UV) and near-infrared (NIR) light spectrum for power conversion. The future applications of this progressive technology will be of developing transparent films for vacuum insulated glazing $[76,80,81]$, translucent vacuum insulation panel [75] and triple vacuum glazing $[82,83$ ] for the purpose of retrofitting [80] it and/or replacing traditional windows with vacuum insulation that will prove an enormous cost saving while modernising the buildings in this $21^{\text {st }}$ century for the reduction of energy requirement and improving the power generation with least compromise of the lighttransmittance.

\section{Conclusions and future work recommendations}

This study provides abridged review of the manifestations of carbon capture \& storage systems and the ambivalence of quantum-dot \& organic solar cells. Following are the summary of the conclusive remarks:

(i) This research implicates that CCS system is evolving in capturing $\mathrm{CO}_{2}$ emissions over the next 50 years. Improvements are believed to achieve a norm to be employed by all coal-fired electrical power stations to further mitigate climate change. CCS systems are ideally a great way of capturing $\mathrm{CO}_{2}$ that is emitted from a typical coal-fired electrical power stations, in order to prevent them from adding to the emissions that enter the atmosphere either in precombustion or post-combustion stages. Although, different manifestations are discussed for capturing and storing the $\mathrm{CO}_{2}$.

(ii) As it currently stands, based on the different CCS systems discussed in this paper, the best method for mitigating climate change with use of CCS within coal-fired electrical power stations is difficult to conclude as each method has its benefits and drawbacks in terms of $\mathrm{CO}_{2}$ capture rates, operating costs, toxicity and energy efficiency. For example, Chemical Looping Combustion appears to be the more energy efficient than Oxy-fuel CFBC and Ionic Liquids, and less expensive than Calcium Looping and Amine Scrubbing. Calcium Looping (Cal) and Ionic Liquids are also less toxic than Amine Scrubbing. The use of chemical solvent in Amine Scrubbing could be problematic but is very effective at removing $\mathrm{CO}_{2}$ emissions, although Ionic Solvent technologies actually counter the need for using amine chemicals. Direct air technology is also very compelling at capturing $\mathrm{CO}_{2}$ emissions, but it is highly expensive system for electrical power stations and not a cost-effective option. Chemical-Looping Combustion has been shown to achieve an $100 \%$ capture rate when combined with IGCC so could be argued to be the most effective CCS technology. The research undertaken in this paper shows that it is challenging to find an appropriate picture of costs, especially as much of these are estimated - because of the fact that these systems have not been widely used in electrical power stations and improvements are still being made. There have been pilots and trials of these systems, but it is clear that more research is needed. A lot of the research is 
very bespoke and delves into other areas such as the use of these systems specifically with vehicles or with use of other emissions, use in other counties, etc.

(iii) Nevertheless, it is abundantly clear that further research is still required for all CCS systems to be able to implement them widely in existing/new electrical power stations, with regards to improving their costs/performance. Combustive waste heat energy recovery systems also play a role besides CCS mitigating climate change as the different systems prevent any wasted heat energy from affecting the environment. Instead, they allow the wasted heat energy to be re-used possibly as a power source for the electrical power station. Although, thermoelectric is a great method, research has heavily hinted that organic Rankine cycle units can improve energy efficiency and reduce emissions. Waste heat energy recovery systems can be used in conjunction with $\mathrm{CO}_{2}$ capture systems for further reduction of emissions impact from electrical power stations on climate change.

(iv) The ambivalence of quantum dot and organic solar cells are briefly reviewed. It implicates that composite film with enhanced quantum dot effects will make the film highly transparent and options of tunability of its colour spectrum make the quantum dot solar cells highly attractive to vacuum insulated glazed windows and translucent vacuum insulation panels. Organic solar cells are carbon-rich polymers and can be designed to improve a precise function of the cell, such as sensitivity to a certain type of light. OPV cells can only be considered as half-competent to crystalline silicon and have smaller beneficial lifespans, but could be less costly to produce in high volumes. Current research issues are substitution/compromises between electrical power conversion efficiency and average visible light transmittance. However, improving average light-transmittance decreases electrical power conversion efficiency and vice versa.

\section{Acknowledgment}

This research work was supported by the international collaborations with co-authors and London South Bank University, Solar Thermal Vacuum Engineering Research Group. This research is selffunded and a self-initiated collaborative research work that did not receive any specific grant from funding agencies in the public, commercial, or not-for-profit sectors.

\section{References}

[1] Memon, S., T. Katsura, A. Radwan, S. Zhang, A. A. Serageldin, E. M. Abo-Zahhad, S. Sergey et al. "Modern eminence and concise critique of solar thermal energy and vacuum insulation technologies for sustainable low-carbon infrastructure." International Journal of Solar Thermal Vacuum Engineering 1, no. 1 (2020): 52-71. ISSN online (2716-6953).

https://doi.org/10.37934/stve.1.1.5271

[2] Owusu, Phebe Asantewaa, and Samuel Asumadu-Sarkodie. "A review of renewable energy sources, sustainability issues and climate change mitigation." Cogent Engineering 3, no. 1 (2016): 1167990. https://doi.org/10.1080/23311916.2016.1167990

[3] Solomon, Susan, Gian-Kasper Plattner, Reto Knutti, and Pierre Friedlingstein. "Irreversible climate change due to carbon dioxide emissions." Proceedings of the national academy of sciences 106, no. 6 (2009): 1704-1709. https://doi.org/10.1073/pnas.0812721106

[4] Zheng, Ligang, ed. Oxy-fuel combustion for power generation and carbon dioxide $\left(\mathrm{CO}_{2}\right)$ capture. Elsevier, (2011). ISBN: 978-1-84569-671-9.

[5] Bell, Lon E. "Cooling, heating, generating power, and recovering waste heat with thermoelectric systems." Science 321, no. 5895 (2008): 1457-1461.

[6] Memon, Saim. "Advanced Thermoelectric Materials for Energy Harvesting Applications." .IntechOpen Publisher, London, ISBN: 978-1-78984-529-7, (2020). 
https://doi.org/10.5772/intechopen.77430

[7] Memon, Saim. "Introductory Chapter: Introduction to Advanced Thermoelectric Materials for Energy Harvesting Applications", Advanced Thermoelectric Materials for Energy Harvesting Applications, IntechOpen, London. (2019). https://doi.org/10.5772/intechopen.89640

[8] Goetzberger, Adolf, Christopher Hebling, and Hans-Werner Schock. "Photovoltaic materials, history, status and outlook." Materials Science and Engineering: R: Reports 40, no. 1 (2003): 1-46. https://doi.org/10.1016/S0927-796X(02)00092-X

[9] Green, Martin A. "Silicon photovoltaic modules: a brief history of the first 50 years." Progress in Photovoltaics: Research and applications 13, no. 5 (2005): 447-455. https://doi.org/10.1002/pip.612

[10] Singh, Girish Kumar. "Solar power generation by PV (photovoltaic) technology: A review." Energy 53 (2013): 1-13. https://doi.org/10.1016/j.energy.2013.02.057

[11] Inganäs, Olle. "Organic photovoltaics over three decades." Advanced materials 30, no. 35 (2018): 1800388. https://doi.org/10.1002/adma.201800388

[12] Boot-Handford, Matthew E., Juan C. Abanades, Edward J. Anthony, Martin J. Blunt, Stefano Brandani, Niall Mac Dowell, José R. Fernández et al. "Carbon capture and storage update." Energy \& Environmental Science 7, no. 1 (2014): 130-189. https://doi.org/10.1039/C3EE42350F

[13] Rochelle, Gary T. "Amine scrubbing for CO2 capture." Science 325, no. 5948 (2009): 1652-1654. https://doi.org/10.1126/science.1176731

[14] Rao, Anand B., and Edward S. Rubin. "A technical, economic, and environmental assessment of amine-based CO2 capture technology for power plant greenhouse gas control." Environmental science \& technology 36, no. 20 (2002): 4467-4475. https://doi.org/10.1021/es0158861

[15] Romeo, Luis M., Irene Bolea, and Jesús M. Escosa. "Integration of power plant and amine scrubbing to reduce CO2 capture costs." Applied Thermal Engineering 28, no. 8-9 (2008): 1039-1046. https://doi.org/10.1016/j.applthermaleng.2007.06.036

[16] Romeo, Luis M., Irene Bolea, and Jesús M. Escosa. "Integration of power plant and amine scrubbing to reduce CO2 capture costs." Applied Thermal Engineering 28, no. 8-9 (2008): 1039-1046. https://doi.org/10.1016/j.applthermaleng.2007.06.036

[17] Ahn, Hyungwoong, Mauro Luberti, Zhengyi Liu, and Stefano Brandani. "Process configuration studies of the amine capture process for coal-fired power plants." International Journal of Greenhouse Gas Control 16 (2013): 29-40. https://doi.org/10.1016/j.ijggc.2013.03.002

[18] Ramdin, Mahinder, Theo W. de Loos, and Thijs JH Vlugt. "State-of-the-art of CO2 capture with ionic liquids." Industrial \& Engineering Chemistry Research 51, no. 24 (2012): 8149-8177. https://doi.org/10.1021/ie3003705

[19] Brennecke, Joan F., and Burcu E. Gurkan. "Ionic liquids for CO2 capture and emission reduction." The Journal of Physical Chemistry Letters 1, no. 24 (2010): 3459-3464. https://doi.org/10.1021/jz1014828

[20] Blamey, J., E. J. Anthony, J. Wang, and P. S. Fennell. "The calcium looping cycle for large-scale CO2 capture." Progress in Energy and Combustion Science 36, no. 2 (2010): 260-279. https://doi.org/10.1016/j.pecs.2009.10.001

[21] Valverde, J. M., P. E. Sanchez-Jimenez, and Luis A. Perez-Maqueda. "Calcium-looping for post-combustion CO2 capture. On the adverse effect of sorbent regeneration under CO2." Applied energy 126 (2014): 161-171. https://doi.org/10.1016/j.apenergy.2014.03.081

[22] Erans, María, Vasilije Manovic, and Edward J. Anthony. "Calcium looping sorbents for CO2 capture." Applied Energy 180 (2016): 722-742. https://doi.org/10.1016/j.apenergy.2016.07.074

[23] Adams II, Thomas A., Leila Hoseinzade, Pranav Bhaswanth Madabhushi, and Ikenna J. Okeke. "Comparison of CO2 capture approaches for fossil-based power generation: review and meta-study." Processes 5, no. 3 (2017): 44. https://doi.org/10.3390/pr5030044

[24] Keith, David W., Minh Ha-Duong, and Joshuah K. Stolaroff. "Climate strategy with CO 2 capture from the air." Climatic Change 74, no. 1-3 (2006): 17-45. https://doi.org/10.1007/s10584-005-9026-x

[25] Ranjan, Manya, and Howard J. Herzog. "Feasibility of air capture." Energy Procedia 4 (2011): 2869-2876. https://doi.org/10.1016/j.egypro.2011.02.193 
[26] Mathieu, P. "Oxyfuel combustion systems and technology for carbon dioxide (CO2) capture in power plants." In Developments and Innovation in Carbon Dioxide (CO2) Capture and Storage Technology, pp. 283-319. Woodhead Publishing, 2010. https://doi.org/10.1533/9781845699574.3.283

[27] Ishida, M., and H. Jin. "CO2 recovery in a power plant with chemical looping combustion." Energy Conversion and Management 38 (1997): S187-S192.

[28] Hossain, Mohammad M., and Hugo I. de Lasa. "Chemical-looping combustion (CLC) for inherent CO2 separationsa review." Chemical Engineering Science 63, no. 18 (2008): 4433-4451.

https://doi.org/10.1016/j.ces.2008.05.028

[29] Mantripragada, Hari C., and Edward S. Rubin. "Chemical looping for pre-combustion CO2 capture-performance and cost analysis." Energy procedia 37 (2013): 618-625.

[30] Mukherjee, Sanjay, Prashant Kumar, Aidong Yang, and Paul Fennell. "Energy and exergy analysis of chemical looping combustion technology and comparison with pre-combustion and oxy-fuel combustion technologies for CO2 capture." Journal of environmental chemical engineering 3, no. 3 (2015): 2104-2114. https://doi.org/10.1016/j.jece.2015.07.018

[31] Adanez, Juan, Alberto Abad, Francisco Garcia-Labiano, Pilar Gayan, and F. Luis. "Progress in chemical-looping combustion and reforming technologies." Progress in energy and combustion science 38, no. 2 (2012): 215-282. https://doi.org/10.1016/j.pecs.2011.09.001

[32] Mattisson, Tobias, and Anders Lyngfelt. "Applications of chemical-looping combustion with capture of CO2." Second Nordic Minisymposium on CO2 Capture and Storage, Göteborg, Sweden (2001).

[33] Stanger, Rohan, Terry Wall, Reinhold Spörl, Manoj Paneru, Simon Grathwohl, Max Weidmann, Günter Scheffknecht et al. "Oxyfuel combustion for $\mathrm{CO} 2$ capture in power plants." International Journal of Greenhouse Gas Control 40 (2015): 55-125.

https://doi.org/10.1016/j.ijggc.2015.06.010

[34] Kunze, Christian, and Hartmut Spliethoff. "Assessment of oxy-fuel, pre-and post-combustion-based carbon capture for future IGCC plants." Applied Energy 94 (2012): 109-116. https://doi.org/10.1016/j.apenergy.2012.01.013

[35] Mondal, Monoj Kumar, Hemant Kumar Balsora, and Prachi Varshney. "Progress and trends in CO2 capture/separation technologies: a review." Energy 46, no. 1 (2012): 431-441. https://doi.org/10.1016/j.energy.2012.08.006

[36] Hu, Yukun, and Jinyue Yan. "Oxyfuel Combustion for CO2 Capture." Handbook of Clean Energy Systems (2015): 129.

[37] Espatolero, Sergio, and Luis M. Romeo. "Optimization of oxygen-based CFBC technology with CO2 capture." Energy Procedia 114 (2017): 581-588. https://doi.org/10.1016/j.egypro.2017.03.1200

[38] Memon, Saim, and Khawaja Noman Tahir. "Experimental and analytical simulation analyses on the electrical performance of thermoelectric generator modules for direct and concentrated quartz-halogen heat harvesting." Energies 11, no. 12 (2018): 3315.

https://doi.org/10.3390/en11123315

[39] Memon, Saim, Maekele Mihreteab, Takao Katsura, Ali Radwan, Shanwen Zhang, Ahmed A. Serageldin, and Essam M. Abo-Zahhad. "Experimental and theoretical performance evaluation of parabolic trough mirror as solar thermal concentrator to thermoelectric generators." International Journal of Solar Thermal Vacuum Engineering 1, no. 1 (2020): 22-38. ISSN online (2716-6953).

https://doi.org/10.37934/stve.1.1.2238

[40] Makeen, Peter, Hani A. Ghali, and Saim Memon. "Experimental and Theoretical Analysis of the Fast Charging Polymer Lithium-Ion Battery Based on Cuckoo Optimization Algorithm (COA)." IEEE Access 8 (2020): 140486140496. https://doi.org/10.1109/ACCESS.2020.3012913

[41] Khan, Asif, Saim Memon, and T. P. Sattar. "Integration and management of solar energy for electric vehicle charging station." In Solar World Congress 2017-Innovation for the 100\% renewable energy transformation. Abu Dhabi, (2017). ISBN 978-3-981 465 9-7-6. https://doi.org/10.18086/swc.2017.16.03

[42] Khan, Asif, Saim Memon, and Tariq Pervez Sattar. "Analyzing integrated renewable energy and smart-grid systems to improve voltage quality and harmonic distortion losses at electric-vehicle charging stations." IEEE Access 6 (2018): 26404-26415.

https://doi.ord/10.1109/ACCESS.2018.2830187 
[43] Larjola, Jaakko. "Electricity from industrial waste heat using high-speed organic Rankine cycle (ORC)." International journal of production economics 41, no. 1-3 (1995): 227-235. https://doi.org/10.1016/0925-5273(94)00098-0

[44] Hung, Tzu-Chen, T. Y. Shai, and S. Kong Wang. "A review of organic Rankine cycles (ORCs) for the recovery of lowgrade waste heat." Energy 22, no. 7 (1997): 661-667. https://doi.org/10.1016/S0360-5442(96)00165-X

[45] Lu, Yiji, Anthony Paul Roskilly, and Xiaoli Yu. "The Development and Application of Organic Rankine Cycle for Vehicle Waste Heat Recovery." In Organic Rankine Cycle Technology for Heat Recovery, p. 22. IntechOpen, 2018.

[46] Fujishima, Daisuke, Hiroshi Kanno, Toshihiro Kinoshita, Eiji Maruyama, Makoto Tanaka, Makoto Shirakawa, and Kenichi Shibata. "Organic thin-film solar cell employing a novel electron-donor material." Solar energy materials and solar cells 93, no. 6-7 (2009): 1029-1032.

https://doi.org/10.1016/j.solmat.2008.11.034

[47] Huynh, Wendy U., Janke J. Dittmer, and A. Paul Alivisatos. "Hybrid nanorod-polymer solar cells." science 295, no. 5564 (2002): 2425-2427.

https://doi.org/10.1126/science.1069156

[48] Nelson, Jenny. "Organic photovoltaic films." Current Opinion in Solid State and Materials Science 6, no. 1 (2002): 87-95. https://doi.org/10.1016/S1359-0286(02)00006-2

[49] Bukowski, Tracie J., and Joseph H. Simmons. "Quantum dot research: current state and future prospects." Critical Reviews in Solid State and Material Sciences 27, no. 3-4 (2002): 119-142. https://doi.org/10.1080/10408430208500496

[50] Janssen, René AJ, and Jenny Nelson. "Factors limiting device efficiency in organic photovoltaics." Advanced Materials 25, no. 13 (2013): 1847-1858. https://doi.org/10.1002/adma.201202873

[51] Lizin, Sebastien, Steven Van Passel, Ellen De Schepper, Wouter Maes, Laurence Lutsen, Jean Manca, and Dirk Vanderzande. "Life cycle analyses of organic photovoltaics: a review." Energy \& Environmental Science 6, no. 11 (2013): 3136-3149. https://doi.org/10.1039/C3EE42653J

[52] Parida, Bhubaneswari, S_ Iniyan, and Ranko Goic. "A review of solar photovoltaic technologies." Renewable and sustainable energy reviews 15, no. 3 (2011): 1625-1636.

https://doi.org/10.1016/j.rser.2010.11.032

[53] El Chaar, L., and N. El Zein. "Review of photovoltaic technologies." Renewable and sustainable energy reviews 15, no. 5 (2011): 2165-2175. https://doi.org/10.1016/j.rser.2011.01.004

[54] Brabec, Christoph J. "Organic photovoltaics: technology and market." Solar energy materials and solar cells 83, no. 2-3 (2004): 273-292.

https://doi.org/10.1016/j.solmat.2004.02.030

[55] Wang, Xin, Di Liu, and Jiuyan Li. "Organic photovoltaic materials and thin-film solar cells." Frontiers of Chemistry in China 5, no. 1 (2010): 45-60.

[56] Tang, Ching W. "Two-layer organic photovoltaic cell." Applied physics letters 48, no. 2 (1986): 183-185. https://doi.org/10.1063/1.96937

[57] Li, Cheng, Yuhong Chen, Yubing Wang, Zafar Iqbal, Manish Chhowalla, and Somenath Mitra. "A fullerene-single wall carbon nanotube complex for polymer bulk heterojunction photovoltaic cells." Journal of Materials Chemistry 17, no. 23 (2007): 2406-2411. https://doi.org/10.1039/B618518E

[58] Algar, W. Russ, Melissa Massey, and Ulrich J. Krull. "The application of quantum dots, gold nanoparticles and molecular switches to optical nucleic-acid diagnostics." TrAC Trends in Analytical Chemistry 28, no. 3 (2009): 292 306. https://doi.org/10.1016/j.trac.2008.11.012

[59] Weickert, Jonas, Ricky B. Dunbar, Holger C. Hesse, Wolfgang Wiedemann, and Lukas Schmidt-Mende. "Nanostructured organic and hybrid solar cells." Advanced materials 23, no. 16 (2011): 1810-1828. https://doi.org/10.1002/adma.201003991

[60] Dowling, Jonathan P., and Gerard J. Milburn. "Quantum technology: the second quantum revolution." Philosophical Transactions of the Royal Society of London. Series A: Mathematical, Physical and Engineering Sciences 361, no. 1809 (2003): 1655-1674. https://doi.org/10.1098/rsta.2003.1227 
[61] Jun, H. K., M. A. Careem, and A. K. Arof. "Quantum dot-sensitized solar cells-perspective and recent developments: a review of $\mathrm{Cd}$ chalcogenide quantum dots as sensitizers." Renewable and Sustainable Energy Reviews 22 (2013): 148-167.

[62] Gao, Jianbo, Jianbing Zhang, Jao van de Lagemaat, Justin C. Johnson, and Matthew C. Beard. "Charge generation in $\mathrm{PbS}$ quantum dot solar cells characterized by temperature-dependent steady-state photoluminescence." ACS nano 8, no. 12 (2014): 12814-12825. https://doi.org/10.1021/nn506075s

[63] Yang, Chenchen, and Richard R. Lunt. "Limits of visibly transparent luminescent solar concentrators." Advanced Optical Materials 5, no. 8 (2017): 1600851. https://doi.org/10.1002/adom.201600851

[64] Zhang, Shanwen, Min Kong, Hong Miao, Saim Memon, Yanjun Zhang, and Sixing Liu. "Transient temperature and stress fields on bonding small glass pieces to solder glass by laser welding: Numerical modelling and experimental validation." Solar Energy 209 (2020): 350-362. https://doi.org/10.1016/j.solener.2020.09.014

[65] Memon, Saim, Yueping Fang, and Philip C. Eames. "The influence of low-temperature surface induction on evacuation, pump-out hole sealing and thermal performance of composite edge-sealed vacuum insulated glazing." Renewable energy 135 (2019): 450-464. https://doi.org/10.1016/j.renene.2018.12.025

[66] Memon, Saim. "Design, fabrication and performance analysis of vacuum glazing units fabricated with low and high temperature hermetic glass edge sealing materials." PhD diss., Loughborough University, 2013. https://dspace.lboro.ac.uk/2134/14562

[67] Memon, Saim, and Philip C. Eames. "Predicting the solar energy and space-heating energy performance for solidwall detached house retrofitted with the composite edge-sealed triple vacuum glazing." Energy Procedia 122 (2017): 565-570. https://doi.org/10.1016/j.egypro.2017.07.419

[68] Memon, Saim. "Analysing the potential of retrofitting ultra-low heat loss triple vacuum glazed windows to an existing UK solid wall dwelling." International Journal of Renewable Energy Development (IJRED) 3, no. 3 (2014): 161-174.

https://doi.org/10.14710/ijred.3.3.161-174

[69] Memon, Saim, and Philip C. Eames. "Heat load and solar gain prediction for solid wall dwellings retrofitted with triple vacuum glazing for selected window to wall area ratios." In World Renewable Energy Forum, WREF 2012, vol. 6, pp. 4636-4643. ASES, 2012. ISBN: 9781622760923

[70] Fang, Yueping, Saim Memon, Jingqing Peng, Mark Tyrer, and Tingzhen Ming. "Solar thermal performance of two innovative configurations of air-vacuum layered triple glazed windows." Renewable Energy 150 (2020): $167-175$. https://doi.org/10.1016/j.renene.2019.12.115

[71] Memon, Saim, and Philip C. Eames. "Solar energy gain and space-heating energy supply analyses for solid-wall dwelling retrofitted with the experimentally achievable U-value of novel triple vacuum glazing." Journal of Daylighting 4, no. 1 (2017): 15-25. https://doi.org/10.15627/jd.2017.2

[72] Memon, Saim. "Thermal Conductivity Measurement of Vacuum Tight Dual-Edge Seal for the Thermal Performance Analysis of Triple Vacuum Glazing." Impact of Thermal Conductivity on Energy Technologies (2018): 133. http://dx.doi.org/10.5772/intechopen.74255

[73] Memon, Saim. "Design, development and thermal performance analysis of ultra-low heat loss triple vacuum glazing." In Solar World Congress 2017-Innovation for the 100\% renewable energy transformation. Abu Dhabi. (2017) ISBN 978-3-981 465 9-7-6. https://doi.org/10.18086/swc.2017.15.04

[74] Katsura, Takao, Saim Memon, Ali Radwan, Makoto Nakamura, and Katsunori Nagano. "Thermal performance analysis of a new structured-core translucent vacuum insulation panel in comparison to vacuum glazing: Experimental and theoretically validated analyses." Solar Energy 199 (2020): 326-346. https://doi.org/10.1016/j.solener.2020.02.030

[75] Radwan, Ali, Takao Katsura, Saim Memon, Ahmed A. Serageldin, Makoto Nakamura, and Katsunori Nagano. "Thermal and electrical performances of semi-transparent photovoltaic glazing integrated with translucent vacuum insulation panel and vacuum glazing." Energy Conversion and Management 215 (2020): 112920. https://doi.org/10.1016/j.enconman.2020.112920

[76] Memon, Saim, and Philip C. Eames. "Design and development of lead-free glass-metallic vacuum materials for the construction and thermal performance of smart fusion edge-sealed vacuum glazing." Energy and Buildings (2020): 110430. 
https://doi.org/10.1016/j.enbuild.2020.110430

[77] Miao, Hong, Lingcong Zhang, Sixing Liu, Shanwen Zhang, Saim Memon, and Bi Zhu. "Laser Sealing for Vacuum Plate Glass with PbO-TiO2-SiO2-RxOy Solder." Sustainability 12, no. 8 (2020): 3118. https://doi.org/10.3390/su12083118

[78] Zhang, Shanwen, Min Kong, Saim Memon, Hong Miao, Yanjun Zhang, and Sixing Liu. "Thermal Analysis of a New Neutron Shielding Vacuum Multiple Glass." Sustainability 12, no. 8 (2020): 3083. https://doi.org/10.3390/su12083083

[79] Memon, Saim. "Investigating energy saving performance interdependencies with retrofit triple vacuum glazing for use in UK dwelling with solid walls, Sustainable Development on Building and Environment." In Sustainable Development on Building and Environment: Proceedings of the 7th International Conference, 2015. ISBN-13: 9780993120701.

[80] Ahmed, Mostafa, Ali Radwan, Ahmed Serageldin, Saim Memon, Takao Katsura, and Katsunori Nagano. "Thermal Analysis of a New Sliding Smart Window Integrated with Vacuum Insulation, Photovoltaic, and Phase Change Material." Sustainability 12, no. 19 (2020): 7846. https://doi.org/10.3390/su12197846

[81] Memon, Saim, Farukh Farukh, and Karthikeyan Kandan. "Effect of cavity vacuum pressure diminution on thermal performance of triple vacuum glazing." Applied Sciences 8, no. 9 (2018): 1705. https://doi.org/10.3390/app8091705

[82] Memon, Saim. "Experimental measurement of hermetic edge seal's thermal conductivity for the thermal transmittance prediction of triple vacuum glazing." Case studies in thermal engineering 10 (2017): 169-178. https://doi.org/10.1016/j.csite.2017.06.002

[83] Memon, Saim, Farukh Farukh, Philip C. Eames, and Vadim V. Silberschmidt. "A new low-temperature hermetic composite edge seal for the fabrication of triple vacuum glazing." Vacuum 120 (2015): 73-82.

https://doi.org/10.1016/j.vacuum.2015.06.024 